\title{
Low power radiofrequency electromagnetic radiation for the treatment of pain due to osteoarthritis of the knee
}

\author{
Radiazione elettromagnetica a radiofrequenza di bassa potenza \\ per il trattamento del dolore dovuto ad artrosi del ginocchio
}

\author{
L. Alcidi, E. Beneforti, M. Maresca, U. Santosuosso, M. Zoppi \\ Dipartimento di Medicina Interna, Sezione di Reumatologia, Università degli Studi di Firenze
}

\begin{abstract}
RIASSUNTO
In un gruppo di 40 soggetti affetti da artrosi del ginocchio è stato valutato comparativamente l'effetto antalgico indotto da un ciclo di applicazioni di onde elettromagnetiche a radiofrequenza di bassa potenza (RF) e quello indotto da un ciclo di applicazioni di stimolazione elettrica antalgica transcutanea (TENS). La valutazione è stata effettuata mediante una scala visiva analogica per il rilievo dell'intensità del dolore e mediante l'indice funzionale di Lequesne. La ricerca ha permesso di documentare l'effetto antalgico delle applicazioni di RF nell'artrosi del ginocchio; tale effetto è risultato significativamente migliore di quello della TENS.
\end{abstract}

Reumatismo, 2007; 59(2):140-145

\section{INTRODUCTION}

$\mathrm{D}$ ifferent techniques have been used in some rheumatic diseases to induce a therapeutic effect by heating deep tissues. These techniques are commonly known as 'thermotherapy' (1-4). It should be observed that adequate heating of deep tissues cannot be obtained by conduction or convection of heat because the skin and subcutaneous fat are good thermal insulators and because heating is reduced by blood flow in superficial vessels. Heating of deep tissues can instead be obtained by conversion of other forms of energy into heat. Conversion heat is generated by different types of radiations absorbed by deep tissues: when radiation interacts with tissues, some energy is converted into heat. High power radiofrequency electromagnetic radiation (RF), which produces strong thermal energy, has been widely applied in medicine for ablative procedures (5-7). The aim of our study was to investigate whether low power RF could re-

Indirizzo per la corrispondenza:

Prof. Massimo Zoppi

Dipartimento di Medicina Interna, Sezione di Reumatologia

Università degli Studi di Firenze

Viale G. Pieraccini, 18 - 50139 Firenze

E-mail: m.zoppi@dmi.unifi.it duce pain and improve function in osteoarthritis $(\mathrm{OA})$ of the knee.

\section{PATIENTS AND METHODS}

To induce heating of deep tissues, an original apparatus, which delivers low power RF, was built. The therapeutic effects were investigated in a group of patients suffering from painful OA of one knee. In this randomized study, the results obtained by $\mathrm{RF}$ were compared with the results obtained by transcutaneous electrical nerve stimulation (TENS), which is a well known and largely used technique for local analgesic therapy (8-11). The effectiveness of TENS in knee OA has also been demonstrated (12).

The study was approved by the Ethical Committee of the University Hospital of Florence. The study group included 40 out-patients, 6 males and 34 females, whose age ranged from 38 to 82 years (mean \pm SD: $65.7 \pm 10.6$ years). The patients were recruited in the Rheumatology Division of the University of Florence. All the patients reported pain in one knee, lasting no more than three months, and disability. In all the patients, the typical pathologic changes of OA were documented by X-ray ex- 
amination. All the patients fulfilled clinical and radiologic criteria of the American Rheumatism Association for knee OA (13).

The patients were randomly assigned to two groups, each including 20 patients. The patients of the first group ( 2 males and 18 females, whose age ranged from 38 to 81 years; mean \pm SD: $62 \pm 10.9$ ) were treated by low power RF. The schematic diagram of the stimulating apparatus is shown in figure 1 , which is divided into three sections. Section $A$ is a radio-frequency linear amplifier: the output (Out RF) is floating in reference to the electric power of the apparatus: a correct insulation of the patients from the electric power source is consequently obtained. Section B includes a RF generator with a frequency of $500 \mathrm{KHz}$, connected with the linear amplifier of section $\mathrm{A}$, and a feedback system which automatically regulates the output power, so that a prefixed value of skin temperature is steadily maintained; this section also includes two control devices by which the operator fixes the value of skin temperature which must be reached and the maximal RF power which can be delivered during the application period. Section $\mathrm{C}$ includes an interface which calculates the RF power (W), the electric impedance $(Z)$ of the electrodes which are applied to the patient and the value of the temperature $(\mathrm{T})$ measured by the sensor Tc placed between the active electrode and the skin; the actual value of $\mathrm{T}$ is sent through the interface to the section B for the automatic control of delivered RF energy; section $C$ also includes three displays which show $\mathrm{W}, \mathrm{Z}$ and $\mathrm{T}$ values; $\mathrm{W}, \mathrm{Z}$ and $\mathrm{T}$ signals are also sent to a serial connector, so that they may be acquired by a personal computer.

$\mathrm{RF}$ applications were performed according to the following procedure. First of all, two parameters were selected:

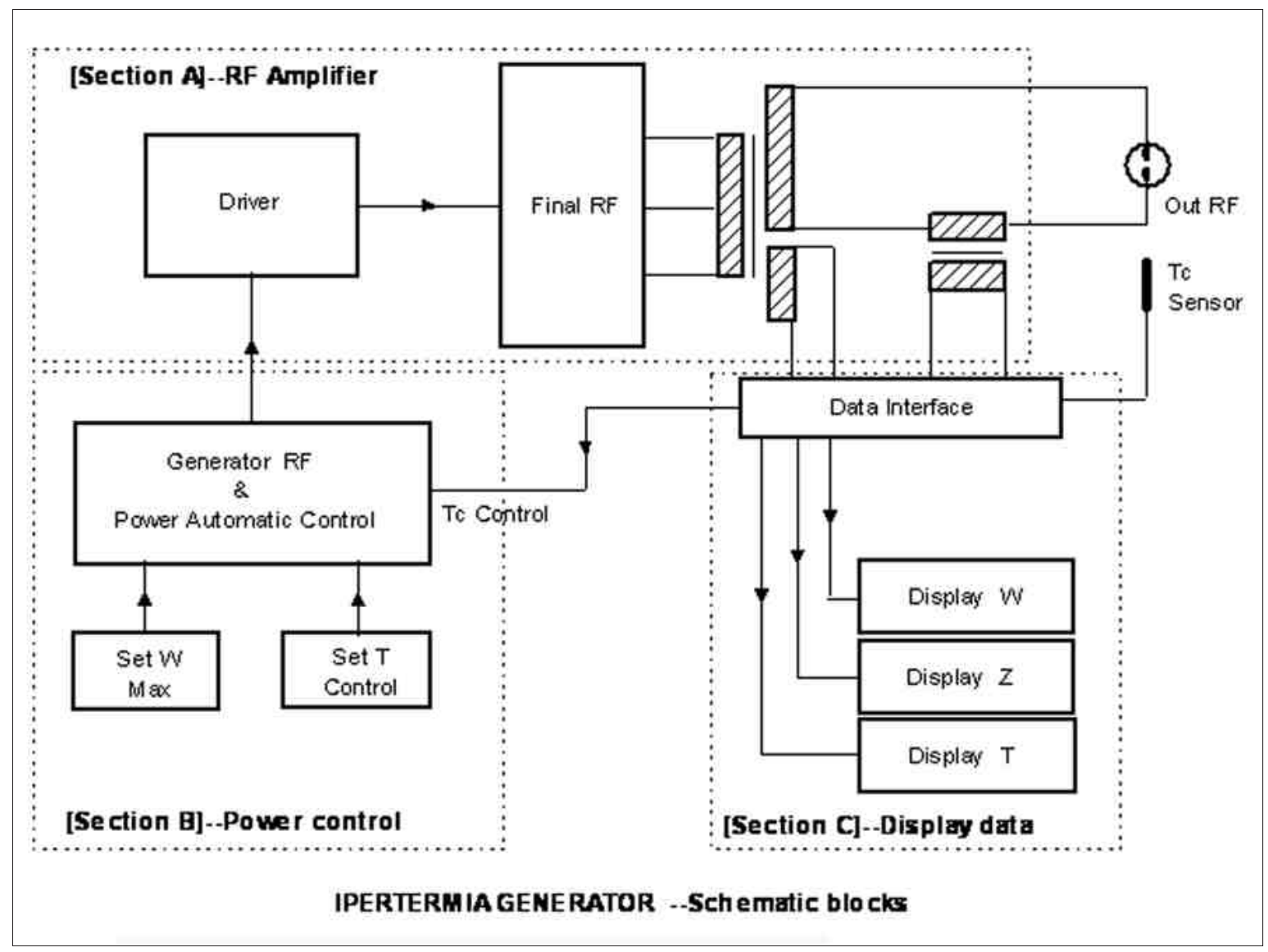

Figure 1 - Schematic diagram of the stimulating apparatus (see text).

A: RF linear amplifier; B: RF generator; C: data interface connected with power, impedance and temperature displays.

RF: radiofrequency; W: power; Z: impedance; T: temperature; Tc: skin temperature. Out RF: output of the RF linear amplifier; Tc sensor: sensor measuring the actual value of skin temperature; Set W max:: device for control of the maximal RF power which can be delivered; Set T control: device for control of the value of skin temperature which must be reached. 
1. the maximal power of RF which could be delivered, i. e. $30 \mathrm{~W}$;

2. he maximal level of $\mathrm{T}$ which could be reached, i.e $42^{\circ} \mathrm{C}$.

The site of application of RF was then chosen. Two rectangular electrodes with incorporated solid gel, connected with the stimulating device, were placed on internal and external sides of the affected knee. The active electrode, with a surface of $40 \mathrm{~cm}^{2}$, connected with a thermocouple, was applied on the internal aspect of the knee; the other electrode (reference electrode), with a surface of $77 \mathrm{~cm}^{2}$, was applied on the external one. The mean delivered specific power was $0.3 \mathrm{~W} / \mathrm{cm}^{2}$. Every period of application lasted $20 \mathrm{~min}$.

Applications were repeated every day at the same hour of the morning for a period of 5 days. The patients were asked to report the sensations they felt during RF application. During every application, power was automatically changed for maintaining the value of prefixed skin temperature. The patient felt a well-tolerated and quite steady warm sensation. An example of data display obtained in one patient during a therapeutic session is shown in figure 2.

The patients of the second group (4 males and 16 females, whose age ranged from 48 to 82 years; means \pm SD: $69.4 \pm 9.2$ ) were treated by TENS. Electrical stimulation was performed according to the technique currently used in our Division: square-wave negative pulses of $0.5 \mathrm{msec}$, repeated with a frequency of $50 \mathrm{~Hz}$, were applied in each patient to the affected knee by means of two rectangular carbon electrodes, each having an area of $25 \mathrm{~cm}^{2}$ : the cathode was placed on the internal aspect of the knee, the anode on the external one. During the stimulation, the intensity of electric

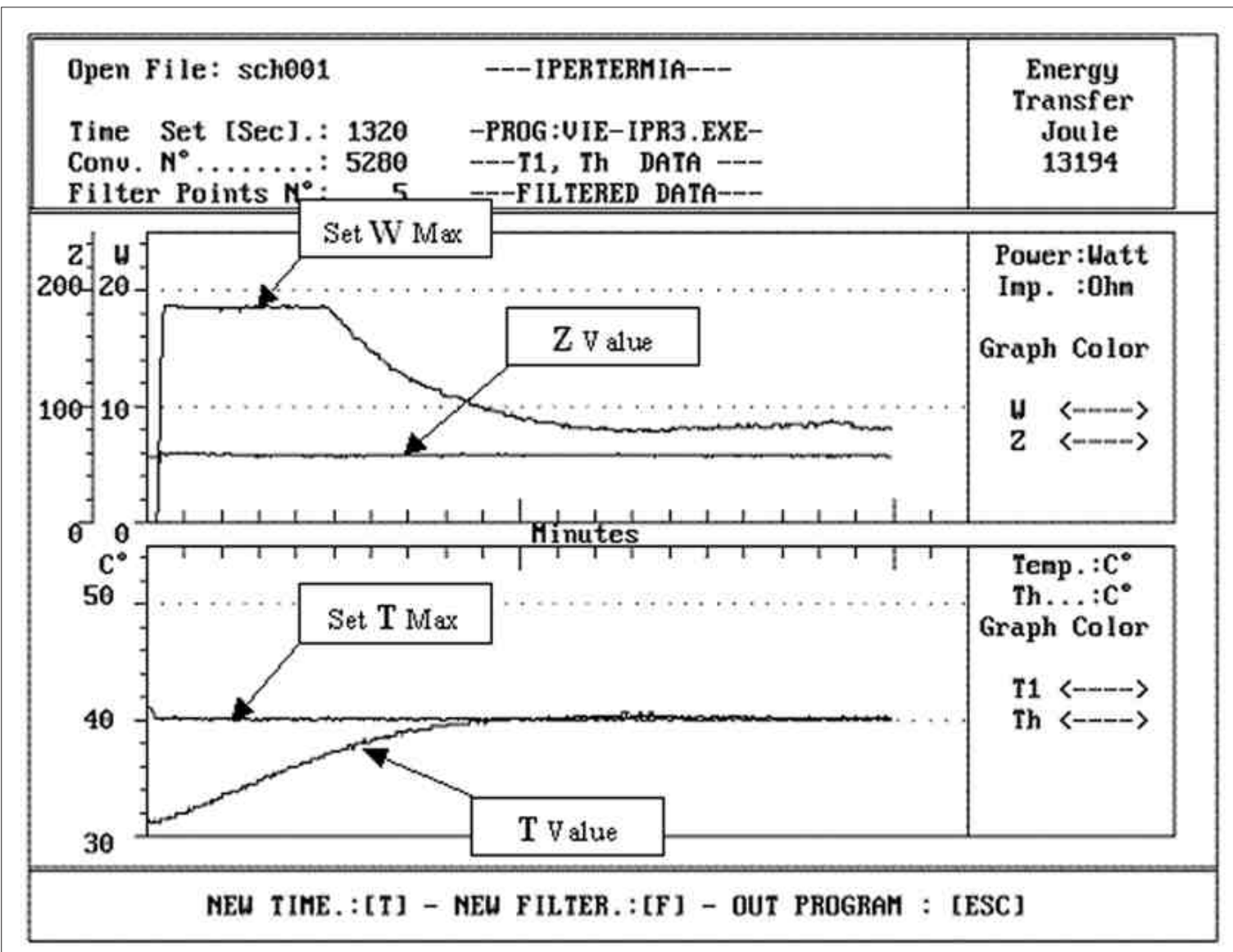

Figure 2 - Example of data display obtained in one patient during a therapeutic session. In this application, the maximal power which could be delivered (Set W Max) had been fixed at a value of $18 \mathrm{~W}$ and the maximal value of temperature which could be reached (Set T Max) was $40^{\circ} \mathrm{C}$. When the value of delivered power is near the set value, the feedback system automatically modifies the value of delivered power, so that skin temperature asymptotically reaches the prefixed value. 
current was regulated to maintain a well-tolerated and stable sensation of tingling. Each period of stimulation lasted $20 \mathrm{~min}$. Sessions were repeated every day for 5 days. In previous investigations (14-16) long lasting analgesic effects were obtained by TENS applied with this technique in patients suffering from different chronic pain syndromes.

To evaluate the therapeutic effect, in each patient of both groups the intensity of pain was assessed by a visual analogue scale (VAS) (17), where 0 means 'no pain' and $100 \mathrm{~mm}$ means 'pain as bad as it could be', and the degree of disability was evaluated using Lequesne's index (18). Lequesne's index for knee OA is composed of 10 items scored on a Likert scale. The items concern:

1. interference of pain with nocturnal rest;

2. morning stiffness;

3. pain exacerbated by maintaining the upright position;

4. pain induced by movement;

5. pain induced by standing up;

6. maximal distance of walking;

7. going up stairs;

8. going down stairs;

9. squatting;

10. walking on an irregular ground.

The total score ranges from 0 to 24 . High scores indicate severe disability. The tests were performed before the therapy, immediately after therapy and 30 days after.

The values of pain intensity and of Lequesne's in- dex of patients of the two groups were compared. Statistical analysis of data was performed by analysis of variance for repeated measures. $\mathrm{P}<0.05$ was considered significant.

\section{RESULTS}

The mean age of the two groups was not significantly different.

The mean values of pain intensity and disability, measured by VAS and by Lequesne's index respectively, evaluated in the two groups of patients before, immediately after and 30 days after the therapy, are reported in table I.

A decrease of the mean values of pain intensity and of Lequesne's index was observed in both groups of patients. In the group of patients treated with $\mathrm{RF}$ a significant difference $(\mathrm{p}<0.01)$ was evident between the basal values of VAS and Lequesne's index and the values observed after the therapy, whereas in the group of patients treated with TENS statistical analysis did not show a significant difference between the basal values of VAS and Lequesne's index and the values observed after the therapy.

\section{DISCUSSION}

In the present study, a significant decrease of VAS and of Lequesne's index was observed after therapy in the group of patients treated with RF. In the

Table I - Mean values \pm DS of pain intensity (VAS) and Lequesne's index in the two groups of patients, with level of statistical significance of the observed differences.

\begin{tabular}{|c|c|c|c|}
\hline \multicolumn{4}{|c|}{ Pan Intensity (VAS) } \\
\hline & Before the therapy & Immediately after therapy & 30 days after therapy \\
\hline Patients treated with RF & $63.85 \pm 20.82$ & $\begin{array}{c}44.40 \pm 26.77 \\
{[p<0.01]}\end{array}$ & $\begin{array}{c}30.11 \pm 29.64 \\
{[p<0.01]}\end{array}$ \\
\hline Patients treated with TENS & $53.85 \pm 25.70$ & $\begin{array}{c}42.75 \pm 26.17 \\
{[p: \text { N.S.] }}\end{array}$ & $\begin{array}{c}33.11 \pm 24.26 \\
{[p: \text { N.S.] }}\end{array}$ \\
\hline \multicolumn{4}{|c|}{ Lequesne's index } \\
\hline Original values & Before the therapy & Immediately after therapy & 30 days after therapy \\
\hline Patients treated with RF & $11.28 \pm 5.02$ & $\begin{array}{c}6.45 \pm 4.84 \\
{[p<0.01]}\end{array}$ & $\begin{array}{l}5.08 \pm 5.67 \\
{[p<0.01]}\end{array}$ \\
\hline Patients treated with TENS & $13.88 \pm 3.81$ & $\begin{array}{c}10.30 \pm 4.21 \\
\text { [p: N.S.] }\end{array}$ & $\begin{array}{l}9.14 \pm 4.54 \\
{[p: \text { N.S.] }}\end{array}$ \\
\hline $\begin{array}{l}\text { RF: low power radiofrequer } \\
\text { TENS: transcutaneous electr }\end{array}$ & $\begin{array}{l}\text { ion } \\
\text { e stimulation }\end{array}$ & & \\
\hline
\end{tabular}


group of patients treated with TENS, the decrease of VAS and Lequesne's index observed after therapy was not statistically significant. Therefore, it may be supposed that, at least for knee OA, the therapeutic action of RF is more effective than the therapeutic action of TENS.

It must be considered that VAS and Lequesne's index are different types of scales of evaluation. VAS is only a measure of pain intensity whereas Lequesne's index is a measure of disability, which is due to pain, but depends also on other factors, such as reduced range of motion of the joint. It must also be considered that VAS is a $100 \mathrm{~mm}$-line with the label 'no pain' at one end and the label 'pain as bad as it could be' at the other end: the patient marks the line at the point corresponding to his pain; the intensity of pain is measured by the distance (in $\mathrm{mm}$ ) between the end of the line corresponding to 'no pain' and the patient's mark. Pain intensity measured by VAS may therefore vary between 0 and 100, and is a direct and subjective assessment of the intensity of pain felt by the patient. Lequesne's index is obtained by the sum of a series of scores related to the assessment of different symptoms (such as interference of pain with nocturnal rest, stiffness, pain provoked by movement) and to the assessment of the degree of impairement of different daily activities (such as walking and going up and down stairs): it may therefore be considered an objective measure of pain and disability. It may be deduced that the improvement induced by RF is chiefly due to pain relief but is also due to functional improvement.

The good therapeutic effect of RF on pain and disability was also long lasting. Immediately after the therapy, a significant decrease of pain intensity and of Lequesne's index was evident. Thirty days after the end of therapy, pain intensity and Lequesne's index were still significantly lower than before the therapy.

In conclusion, from the present study it may be deduced that the analgesic effect of RF in knee OA is better than the analgesic effect of TENS according to VAS and Lequesne's index. Such a difference of the therapeutic effect may be due to the fact that TENS acts only on superficial tissues and nerve terminals, while RF acts increasing superficial and deep tissue temperature.

\section{SUMMARY}

Objective: To investigate the analgesic effect of low power radiofrequency electromagnetic radiation (RF) in osteoarthritis (OA) of the knee.

Methods: In a randomized study on 40 patients the analgesic effect of RF was compared with the effect of transcutaneous electrical nerve stimulation (TENS). RF and TENS applications were repeated every day for a period of 5 days. The therapeutic effect was evaluated by a visual analogue scale (VAS) and by Lequesne's index: tests were performed before, immediately after and 30 days after therapy.

Results: RF therapy induced a statistically significant and long lasting decrease of VAS and of Lequesne's index; TENS induced a decrease of VAS and of Lequesne's index which was not statistically significant.

Conclusions: A therapeutic effect of RF was therefore demonstrated on pain and disability due to knee OA. This effect was better than the effect of TENS, which is a largely used analgesic technique. Such a difference of the therapeutic effect may be due to the fact that TENS acts only on superficial tissues and nerve terminals, while RF acts increasing superficial and deep tissue temperature.

Key words - Knee, osteoarthritis, pain, radiofrequency, TENS.

Parole chiave - Ginocchio, artrosi, dolore, radiofrequenza, elettroanalgesia.

\section{REFERENCES}

1. Lee MHM, Itoh M, Yang G-FW, Eason AL. Physical therapy and rehabilitation medicine. In: Bonica JJ, editor. The Management of Pain, $2^{\text {nd }}$ edn. Philadelphia: Lea and Febiger, 1990; 1769-88.

2. Marks R, Ghassemi M, Duarte R, Van Nguyen GP. A review of the literature on shortwave diathermy as applied to osteo-arthritis of the knee. Physiotherapy 1999; 85: 304-16.
3. Hanada EY. Efficacy of rehabilitative therapy in regional musculoskeletal conditions. Best Pract Res Clin Rheumatol 2003: 17: 151-66.

4. Ones K, Tetik S, Tetik C, Ones N. The effects of heat on osteoarthritis of the lnee. The Pain Clinic 2006; 18 : 67-75.

5. Lopez BC, Hamlyn PJ, Zakrzewska JM. Systematic review of ablative neurosurgical techniques for the treatment of trigeminal neuralgia. Neurosurgery 2004; 54 : 973-82. 
6. Williams MR, Garrido M, Oz MC, Argenziano M. Alternative energy source for surgical atrial ablation. J Card Surg 2004; 19: 201-6.

7. Haemmerich D, Laeseke PF. Thermal tumours ablation: devices, clinical applications and future directions. Int J Hyperthermia 2005; 21: 755-60.

8. Fishbain D, Chabal C, Abbott A, Heine LW, Cutler R. Transcutaneous electrical nerve stimulation (TENS) treatment outcome in long-term users. Clin J Pain 1996; 12: 201-14.

9. Chabal C. Transcutaneous electrical nerve stimulation. In: Loeser JD, editor. Bonica's Management of Pain, $3^{\text {rd }}$ edn. Philadelphia: Lippincott Williams and Wilkins, 2001: 1842-7.

10. Sluka KA, Walsh D. Transcutaneous electrical nerve stimulation: basic science mechanisms and clinical effectiveness. J Pain 2003; 4: 109-21.

11. Barlas P, Lundeberg T Transcutaneous electrical nerve stimulation and acupuncture. In: McMahon SB, Koltzenburg M, editors. Wall and Melzack's Textbook of Pain, $5^{\text {th }}$ edn. Amsterdam: Elsevier, 2006; 583-90.

12. Osiri M, Welch V, Brosseau L, Shea B, Mc Gowen J, Tugwell P, et al. Transcutaneous electrical nerve stimulation for knee osteoarthritis. Cochrane Database Syst Rev 2000; (4): CD002823.
13. Altman R, Asch E, Bloch D, Bole G, Borenstein D, Brandt K, et al. Development of criteria for the classification and reporting of osteoarthritis. Classification of osteoarthritis of the knee, Diagnostic and Therapeutic Criteria Committee of the American Rheumatism Association. Arthritis Rheum 1986; 29: 1039-49.

14. Zoppi M, Francini F, Maresca M, Procacci P. Changes of cutaneous sensory thresholds induced by non-painful transcutaneous electrical nerve stimulation in normal subjects and in subjects with chronic pain. J Neurol Neurosurg Psychiat 1981; 44: 708-17.

15. Francini F, Maresca M, Procacci P, Zoppi M. The effects of non-painful transcutaneous electrical nerve stimulation on cutaneous pain threshold and muscular reflexes in normal men and in subjects with chronic pain. Pain 1981; 11: 49-63.

16. Procacci P, Maresca M, Cersosimo RM. Twenty years experience with transcutaneous electric stimulation. Schmerz/Pain/Douleur 1990; 11: 22-4.

17. Scott J, Huskisson EC. Graphic representation of pain. Pain 1976; 2: 175-84.

18. Lequesne MG, Mery C, Samson M, Gerard P. Indexes of severity for osteoarthritis of the hip and knee. Validation-value in comparison with other assessment tests. Scand J Rheumatol 1987; 65: 85-9. 